BMJ Paediatrics Open

\title{
Assessment of school readiness of children and factors associated with risk of inadequate school readiness in Ujjain, India: an observational study
}

Shreya Shrivastava, ${ }^{1}$ Vandana Patil, ${ }^{1}$ Madhavi Shelke, ${ }^{2}$ Madhura Anvikar, ${ }^{2}$ Aditya Mathur, ${ }^{1}$ Ashish Pathak ${ }^{\bullet 1,3,4}$

\section{ABSTRACT}

Objective School readiness is a condition or state indicating that the child is ready to learn in a formal educational set-up. The objective of this study was to estimate the prevalence of and factors associated with school readiness in urban schoolchildren in Ujjain, India. Methods This cross-sectional study was conducted from February 2016 to March 2017. Two English-medium schools were conveniently selected. All children aged 5-7 years were eligible to participate. A subscale of Differential Ability Scales-Second Edition, namely 'school readiness scale', was used to assess school readiness in three major domains - early number concept, matching letterlike forms and phonological processing. Data on factors associated with school readiness were collected through parent interview. Quantile regression analysis was used to explore school readiness scores.

Results This study included 203 school-going children (105 boys and 98 girls) having a mean (SD) age of $67.7( \pm 0.51)$ months. The phonological processing and matching letter-like forms had $31.5 \%$ and $30.5 \%$ children, respectively, in lower quantiles ( $\leq 25 \mathrm{th})$. The higher quantile ( $\geq 75$ th) scores were achieved for phonological processing and early number concept $(47.7 \%$ and $44.8 \%$ children, respectively). The results of quantile regression showed negative association of school readiness scores with age of children, lower socioeconomic status and hospitalisation status, especially in the lower quantiles ( $\leq 25 \mathrm{th})$. The 10th, 50th and 75th quantile scores were positively correlated with the increasing education status of the mother. Birth weight was positively associated with the median and higher quantile scores ( $\geq 75$ th).

Conclusions School readiness in a middle-class urban setting in India was negatively associated with lower age of the child, lower socioeconomic status, hospitalisation and positively correlated with increasing birth weight and maternal education. Lower quantile scores were achieved in matching letter-like forms, which measures complex visual-spatial processing, and phonological ability, which correlates with acquired verbal concepts. Focused interventions are needed to improve these skills.

\section{INTRODUCTION}

School readiness is a developmental stage where a child can learn easily, effectively

\section{What is known about the subject?}

Globally, school readiness is considered a framework for improving equity in access to education and in learning outcomes and achieving full developmental potential among young children.

- School readiness has direct gains to the recipients, that is, children, families and schools.

- Globally risk factors for inadequate school readiness are not well studied.

\section{What this study adds?}

School readiness scale, a subset of Differential Ability Scales-Second Edition, can be used to assess school readiness.

- The study shows a negative association of school readiness scores with age of children, socioeconomic status and hospitalisation status, especially in the lower quantile scores ( $\leq 25$ th). Lower quantile scores were achieved in matching letter-like forms, which measures complex visual-spatial processing, and phonological ability, which measures acquired verbal concepts.

and without emotional disturbance. ${ }^{1}$ School readiness implies that formal education will be advantageous to a child because the child has attained the basic minimum skills and knowledge in language, cognitive, psychomotor and socioemotional domains that will enable him or her to be successful in school. ${ }^{1}$ School readiness includes the readiness of the individual child, readiness of the school and the ability of the family and community to support optimal early child development. ${ }^{2}$ Globally, school readiness is regarded as a strategy that promotes equity and enhances performance in school-age children and in adults. ${ }^{3}$

The Constitution of India under Article 45 (1950) stipulates that the Government 


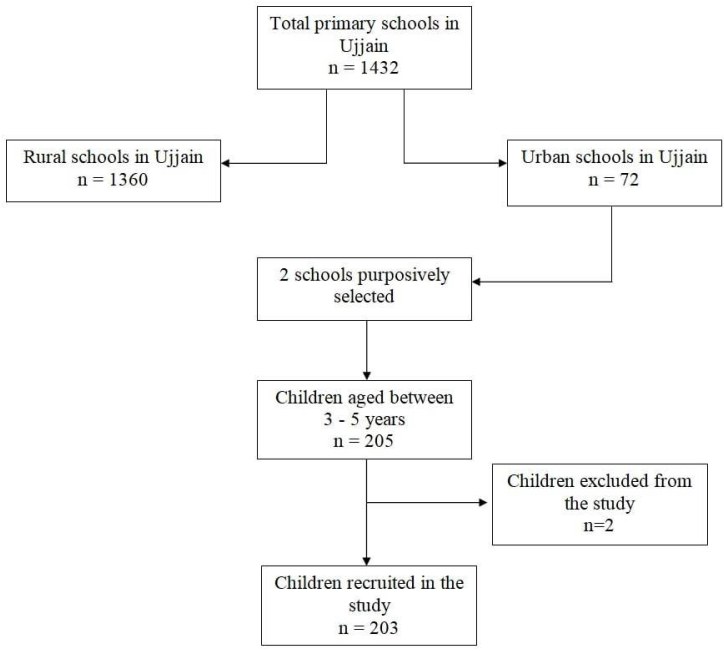

Figure 1 Flow chart showing process of selection of 203 children from two schools of Ujjain, India (for details of schools in Ujjain district please refer to ref ${ }^{12}$ ).

of India provides free and compulsory education for all children until 14 years of age. ${ }^{4}$ However, the Right of Children to Free and Compulsory Education Act 2009 excluded children aged less than 6 years from its gambit. ${ }^{4}$ This lack of focus on Early Childhood Care and Education (ECCE) can seriously derail the ambitious 'Right to Education for All' agenda of the Government of India. Owing to the efforts of policymakers, parents and schools, over the past 10 years, more than $90 \%$ of Indian children have been enrolled in an elementary school. ${ }^{56}$ Nearly $75 \%$ of all 4 -year-old rural Indian children are enrolled in anganwadis (ECCE centres). ${ }^{5}$ India has 1.3 million anganwadis in which 70 million children aged 3-6years are enrolled, making it the largest publicfunded community-based rural ECCE programme in the world. ${ }^{5}$ Despite high enrolment rates in elementary schools, India has high dropout rates in primary and secondary school levels, predominantly due to the poor quality of services provided. ${ }^{45}$ The trend in India is to enrol children in private preschools, with nearly $30 \%$ of rural children enrolled in them. ${ }^{5}$ These private preschools are preferred by the aspirational middle-class parents to teach children English language and reading and writing skills to facilitate entry in a private urban primary school. A few studies on school readiness have been conducted in India. ${ }^{6}$ The India Early Childhood Education Impact Study was conducted in three states, Andhra Pradesh, Assam and Rajasthan, including 1889 preschool facilities, which reported school readiness prevalence to be $27.5 \%-$ $42.5 \% .^{5}$ Another Indian study reported that preschool programmes can increase retention rates of children in primary grades by $8 \%-20 \%{ }^{7}$ School readiness sets the course for a child's future learning, self-concept and success, helping young children to attain their full developmental potential. ${ }^{3}$ However, currently, a comprehensive policy for school readiness is not implemented in India. ${ }^{6}$ Therefore, to fill in the research gap regarding the school readiness of Indian children, the primary objective of the study was to estimate the school readiness prevalence and the secondary objective was to identify the factors associated with school readiness in urban school-going children in Ujjain district, Madhya Pradesh (MP), India.

\section{METHODS \\ Study site}

The Ujjain district where the present study was conducted has a population of 1.9 million with female to male per thousand ratio of 958 in urban and 975 in rural areas. ${ }^{8}$ About $61 \%$ of population lives in the rural areas. ${ }^{8}$ The key population and household profile, such as population below 15 years, sex ratio, literacy rates, fertility rates, household with safe drinking water, cooking fuel and electricity, and maternal and child characteristics, are described in National Family Health Survey- $4 .{ }^{9}$ The Multidimensional Poverty Index (MPI) 2018 showed that the state of MP ranked third among all states with an MPI of 0.180 against national average of 0.121 , indicating high acute poverty. ${ }^{10}$ The Ujjain city is a typical regional city having $30 \%-50 \%$ of new middle-class population, which spends between US $\$ 2$ and US $\$ 10$ per capita per day. ${ }^{11}$

\section{Study population, data collection and design}

This cross-sectional study was conducted from February 2016 to March 2017. Figure 1 shows the number of primary schools in Ujjain city ${ }^{12}$ and the process of selection of two schools from which children were enrolled in the study. English-medium schools were selected by convenience sampling. The selection was based on the willingness of the school administration to participate in the study. All children aged 5-7years were eligible to participate. This age group included the students of three grades from kindergarten, first year to first grade. The inclusion criterion was age between 5 and 7 years irrespective of grade. Apart from refusal to participate there were no other exclusion criteria. The parents of eligible children were approached to participate in the study, and written informed consent was obtained from them. Data on possible child and parent-related factors associated with school readiness were collected through parent interview using a predesigned questionnaire (online supplementary file). The questionnaire was developed with the help of the parents of the children included in this study and after literature review. The questionnaire was pilot tested on 10 children which were not included in the study. In order to minimise selection bias all eligible parents were approached by the researchers irrespective of caste, geographical location or socioeconomic status (SES). In order to minimise recall bias findings were collaborated with documentary evidence.

\section{Study definitions}

The signs and symptoms, care sought and SES were reported by parent interview. Birth weight was recorded from birth records directly. Low birth weight was defined 
as birth weight of less than $2500 \mathrm{~g}$. Diarrhoea was defined as the passage of three or more loose or watery stools in a 24-hour period ${ }^{13}$; loose stool was defined as a stool that takes the shape of the container. ${ }^{13}$ The modified Kuppuswamy scale was used to identify the SES of the family. This scale considers a composite score of education and occupation with the total monthly family income. $^{14}$

\section{Measures}

The school readiness scale, a diagnostic subset of Differential Ability Scales-Second Edition (DAS-II), was used to assess school readiness. ${ }^{15}$ DAS-II is not validated in Indian children and school readiness subset has not been used previously to study school readiness. The school readiness subset tests the child's knowledge in three domains: (A) early number concept, which measures complex verbal and non-verbal mental processing abilities, (B) matching letter-like forms, which is a measure of complex visual-spatial processing, and (C) phonological ability, which measures acquired verbal concepts. ${ }^{15}$ Raw scores and transformed scores were calculated using the table in DAS-II manual. ${ }^{15}$ All assessments and interviews were done in the school. To minimise measurement bias school readiness subset was scored in double by two independent paediatricians.

\section{Training and quality control}

A paediatric clinical psychologist with 12 years' experience and a paediatric neurologist with 14 years' experience supervised the 3-day training and standardisation of DAS-II on 25 children.

\section{Sample size calculation}

An Indian study reported the prevalence of school readiness between $27.8 \%$ and $42.5 \%$ over a 3 -year period. ${ }^{5}$ Sample size estimation was done post hoc for one sample comparison of proportion to detect at least $15 \%$ difference in the proportion around the reported prevalence of $27.5 \%-42.5 \%$, with two-sided alpha of 0.05 and power of $80 \%$. The estimated minimum sample size was in the range of 172-187 (for lower and higher prevalence, respectively).

\section{Data management and statistical analysis}

Data were entered into EpiData Entry (V.3.1, EpiData Software Association, Odense, Denmark), and statistical analysis was performed using Stata (V.13.0, StataCorp, Texas, USA). For continuous variables, range, mean and SD are presented. Categorical independent variables were investigated using the Pearson $\chi^{2}$ test. In case of cell count less than 5 or at least 1 cell count equal to zero, the variable was excluded from further analyses.

A multivariate quantile regression model was used to test the association between school readiness and other independent variables. ${ }^{16}$ Quantile regression model was chosen to capture the full distribution of the outcome-school readiness. The coefficient (b), SE and 95\% CI were estimated for 10th, 25th, 50th (median), 75th and 90th quantiles of school readiness based on 500 bootstrap samples. All analysis was performed using the simultaneous quantile regression command in Stata (V.13.0, StataCorp, Texas, USA). A p value $<0.05$ was considered significant.

\section{Patient and public involvement}

The study concept was as a result of experience of research team with the parents of preschool children over the last 20 years. The parents were involved in the questionnaire development. The results of school readiness were shared in plain language with the parents and their teachers in parent-teacher meetings.

\section{RESULTS}

Figure 1 shows the flow chart of total primary schools available in Ujjain district and the process of selection of 203 children from two schools. Of the 203 children, 105 (52\%) were boys and 98 (48\%) were girls. The mean (SD) age of the children was $67.7( \pm 6.2)$ months, with a range of $60-84$ months. Children included in the study had been to a playschool for a mean duration of $1.94(\mathrm{SD} \pm 0.46)$ years. The distribution of descriptive statistics of the child-related and the family-related factors of the children included in the study is shown in tables 1 and 2, respectively.

\section{Internal validity}

During the study the school readiness subset was scored in double. The inter-rater reliability coefficient was calculated for the entire study and was excellent (intraclass correlation coefficient $($ ICC $)=0.88-0.94$ ). A good internal validity was achieved by Cronbach's alpha coefficient for school readiness scale of 0.86 . The ICC and Cronbach's alpha coefficient were done as DAS-II is not validated for Indian children.

\section{School readiness scores}

The mean total percentile school readiness score in the study was 79.61 (ranging from 10 to 99.9) with SD of \pm 18.27 and $95 \%$ CI of 77.08 to 82.14 , the median (IQR) was 81 (26). The mean (SD) of the $\mathrm{T}$ scores and the 10th, 25th, 50th (median), 75th and 90th quantiles and percentile of the school readiness scores of the children are shown in table 3 .

A total of $64(31.5 \%)$ and $62(30.5 \%)$ children had scores in lower quantiles (25th quantile or below) for phonological processing and matching letter-like forms, respectively. A total of $97(47.7 \%)$ and 91 (44.8\%) children had scores in higher quantiles (75th quantile or above) for phonological processing and early number concept, respectively. Therefore, in the phonological processing domain either children performed very well or poorly. Least mean and median scores were reported for the matching letter-like forms (table 3).

\section{Multivariate analysis}

Table 4 reports the results of multivariate quantile regression analysis. Age of children and lower SES were negatively correlated with school readiness scores at lower quantiles (25th and below) in regression analysis (table 4). 


\begin{tabular}{|c|c|c|}
\hline & $n(n=203)$ & $\%$ \\
\hline \multicolumn{3}{|l|}{ Sex } \\
\hline Boys & 105 & 52 \\
\hline Girls & 98 & 48 \\
\hline \multicolumn{3}{|l|}{ Age (years) } \\
\hline $5-6$ & 162 & 80 \\
\hline$>6-7$ & 41 & 20 \\
\hline \multicolumn{3}{|l|}{ Birth weight (kg) } \\
\hline$>2.5$ & 134 & 66 \\
\hline$<2.5$ & 69 & 34 \\
\hline \multicolumn{3}{|l|}{ Type of delivery } \\
\hline Normal & 165 & 81 \\
\hline Caesarean & 38 & 19 \\
\hline \multicolumn{3}{|l|}{ Handedness } \\
\hline Right handed & 168 & 83 \\
\hline Left handed & 35 & 17 \\
\hline \multicolumn{3}{|c|}{ Time spent by mother with the child } \\
\hline More than 4 hours & 187 & 92 \\
\hline Less than 4 hours & 16 & 8 \\
\hline \multicolumn{3}{|c|}{ Time spent by father with the child } \\
\hline More than 4 hours & 67 & 33 \\
\hline Less than 4 hours & 136 & 67 \\
\hline \multicolumn{3}{|c|}{ Playground visit with parents } \\
\hline Yes & 131 & 65 \\
\hline No & 72 & 35 \\
\hline \multicolumn{3}{|l|}{ Parents teaching } \\
\hline Yes & 125 & 62 \\
\hline No & 78 & 38 \\
\hline \multicolumn{3}{|l|}{ Loose stools } \\
\hline No & 166 & 82 \\
\hline Yes & 37 & 18 \\
\hline \multicolumn{3}{|c|}{ Hospitalisation in the past 3 months } \\
\hline No & 186 & 92 \\
\hline Yes & 17 & 8 \\
\hline
\end{tabular}

Increasing birth weight was positively associated with the median (50th) and higher (75th or more) quantiles in regression analysis (beta coefficient $(b)=18.16 ; p=0.003$, $b=7.30 ; p=0.001, b=3.25 ; p=0.045)$. Time spent by mother was negatively correlated although not statistically significant for lower quantile but was positively associated at 75 th quantile ( $b=1.97 ; p=0.013$ ). Parents teaching the child was not associated with school readiness except at 75 th quantile where it was negatively correlated $(b=-5.54 ; \mathrm{p}=0.001)$. Hospitalisation in the past 3 months was negatively correlated across all percentiles and more prominent effect was seen in lower quantiles ( $\leq 25$ th quantile). Increasing mother education was positively correlated with school readiness in
Table 2 Distribution of family-related factors among 203 school-going children aged 5-7 years in Ujjain, India

\begin{tabular}{lcc}
\hline & $\mathbf{n}(\mathbf{n = 2 0 3 )}$ & $\%$ \\
\hline Religion & & \\
\hline Non-Hindu & 21 & 10 \\
\hline Hindu & 182 & 90 \\
\hline Socioeconomic status ${ }^{*} \dagger$ & & \\
\hline Upper and middle & 174 & 86 \\
\hline Lower & 29 & 14 \\
\hline Mother's education & & \\
\hline HSS or higher & 115 & 57 \\
\hline No or mid-school & 88 & 43 \\
\hline Resident & & \\
\hline Rural & 53 & 150 \\
\hline Urban & 26 & 74 \\
\hline Family type & & \\
\hline Nuclear & 120 & 59 \\
\hline Joint & 83 & 41 \\
\hline Family members & & 40 \\
\hline $\begin{array}{l}\text { (>4) } \\
\text { (<4) }\end{array}$ & 82 & 60 \\
\hline
\end{tabular}

*Modified Kuppuswamy classification.

†Father's education, father's occupation and monthly income are included in modified Kuppuswamy classification.

łIndian rupees.

HSS, higher secondary school.

10th, 50th and 75th quantiles (table 4). Loose stools and family type were not correlated with school readiness score across quantiles.

\section{DISCUSSION}

In this study, we analysed 203 school-going children (105 boys and 98 girls) aged 5-7 years (mean age 5.63 years; $\mathrm{SD} \pm 0.51$ ). The demographic characteristics of the children are included in tables 1 and 2. Approximately one-third of the total children had scores in lower quantiles in phonological processing and matching letter-like forms. The least mean and median scores were reported in the matching letter-like forms. However, majority of the children had scores in higher quantiles in phonological processing and early number concept. The age of children and lower SES had a negative effect as seen in lower quantiles (25th and below) of school readiness score. The median and higher quantiles of school readiness scores were positively associated with birth weight, and only at 75 th quantile, they were associated with parents teaching. Time spent by mother was positively associated only with the 75th quantile of school readiness scores. Negative correlation of school readiness was seen with hospitalisation in the past 3 months in all the quantiles but was more so for lower quantiles ( $\leq 25$ th quantile). A 
Table 3 Distribution of early number concept, matching letter-like forms and phonological process and school readiness among 203 school-going children aged 5-7 years in Ujjain, India

\begin{tabular}{|c|c|c|c|c|c|c|c|c|c|}
\hline \multirow[b]{2}{*}{ Subsets } & \multicolumn{4}{|c|}{ Total children } & \multicolumn{5}{|c|}{ Quantiles (number of children) } \\
\hline & $\mathbf{n}$ & $\begin{array}{l}\text { Mean T } \\
\text { score }\end{array}$ & $\begin{array}{l}\text { Mean } \\
\text { percentile } \\
\text { score }\end{array}$ & $\begin{array}{l}\text { SD } \\
( \pm)\end{array}$ & 10th & 25th & $\begin{array}{l}\text { 50th } \\
\text { (median) }\end{array}$ & 75th & 90th \\
\hline $\begin{array}{l}\text { Early number } \\
\text { concept }\end{array}$ & 203 & 63 & 81.67 & 15.85 & $62(21)$ & $73(31)$ & $82(60)$ & $96(43)$ & $99.8(48)$ \\
\hline $\begin{array}{l}\text { Matching letter- } \\
\text { like forms }\end{array}$ & 203 & 56 & 66.01 & 21.27 & $38(22)$ & $54(40)$ & $69(55)$ & $79(41)$ & $98(45)$ \\
\hline $\begin{array}{l}\text { Phonological } \\
\text { process }\end{array}$ & 203 & 62 & 81.49 & 15.47 & $62(26)$ & $76(38)$ & $84(42)$ & $92(48)$ & $98(49)$ \\
\hline School readiness & 203 & 180 & 79.61 & 18.27 & $61(25)$ & $70(27)$ & $81(50)$ & $96(62)$ & 99 (39) \\
\hline
\end{tabular}

positive association of mother's education was seen with school readiness in 10th, 50th and 75th quantiles.

School readiness is one of the crucial milestones in child development, but at present, it is neglected globally, including in India. ${ }^{6}$ In the current study, we used the school readiness subscale of the DAS-II to assess school readiness in the study population. Measuring school readiness is difficult as no widely used and accepted instruments or scales exist. The Australian Early Development Census (AEDC) measures young child development at the start of the first year of school. ${ }^{17}$ Until now, the AEDC was conducted four times. In the last survey, conducted in 2018, more than $96 \%$ of the eligible Australian children were included in the survey. ${ }^{17}$ The Early Development Instrument (EDI) developed in Canada is a feasible, acceptable and psychometrically sound measurement instrument to assess development health in school. ${ }^{18}$ In addition to language and cognitive skills measured using DAS-II school readiness, the EDI additionally measures physical health and well-being, social competence and emotional maturity (including behavioural assessment and hyperactivity) ${ }^{18}$ However, the main challenge with widespread use of these instruments from the Indian context is to translate them in vernacular languages and further validate them.

Phonological awareness refers to an individual's knowledge that words consist of separate sounds. ${ }^{19}$ Evidence exists that phonological awareness is the predictor of early number skills. Therefore, the early number concept and phonological skills and working memory are linked in preschool children. ${ }^{19}$ The same was seen in our study where most $(\mathrm{n}=97,47.7 \%)$ children had better scores (score 75th quantile or above) in phonological processing and early number concept $(\mathrm{n}=91,44.8 \%)$. Strong phonological processing is required for successful beginning readers. Both early number concept and phonological processing are affected by training. Primary biological or innate abilities use the approximate number system to help distinguish small from large, big from small, empty from full, and others. ${ }^{20}$ Primary biological abilities can be improved with deliberate practice to attain secondary biological abilities like counting, making comparisons and performing arithmetic operations. ${ }^{20}$
The good performance of children in early number concept and phonological skill results may be due to (A) the time spent by the mother with the child and time spent in school, and (B) the time spent by the children in preschool. Moreover, good early number knowledge predicts good school performance in arithmetic tasks, even after controlling for mental ability, memory and intelligence. ${ }^{21}$ Therefore, the arithmetic performance of our children could be evaluated in additional studies.

Matching letter-like forms can be identified based on visual coding development as suggested by Palmer. ${ }^{22}$ Matching letter-like forms checks for visual perceptions which are needed to learn reading and developing of attention span. Ability to read and attention span are important for learning at school. ${ }^{23}$ In our study, 62 $(30.5 \%)$ of the children did not perform adequately (score 25th quantile or below) in matching letter-like forms. Because most $(80 \%)$ of the children included in our study were aged 5-6years, they probably used only visual coding and not both visual and phonological coding strategies (dual coding) ${ }^{23}$ and thus performed poorly in matching letter-like forms.

In our study, the age of children was negatively associated with school readiness scores at lower quantiles (25th and lower). Child age is correlated with math skills, reading skills and learning presocial skills. ${ }^{24}$ In India, girls are at a disadvantage, especially in terms of access to healthcare and nutrition. However, school readiness might be lower among boys than girls. ${ }^{24} 25$ This may be because girls have better fine motor skills, perception and perceptual motor skills than boys. ${ }^{26}$ Lower SES is associated with inadequate school readiness. Children from low-income families tend to experience negative developmental outcomes, including language abilities, working memory, cognitive control, less success in school and lower incomes during adulthood. ${ }^{561724}$ Mother's education can be a proxy for SES. Children of highly educated mothers scored higher in kindergarten number knowledge, vocabulary, math and reading. ${ }^{27}$ Furthermore, low birthweight children are at a higher risk of cognitive and school performance problems compared with normal birthweight children, and the risk of adverse outcomes 


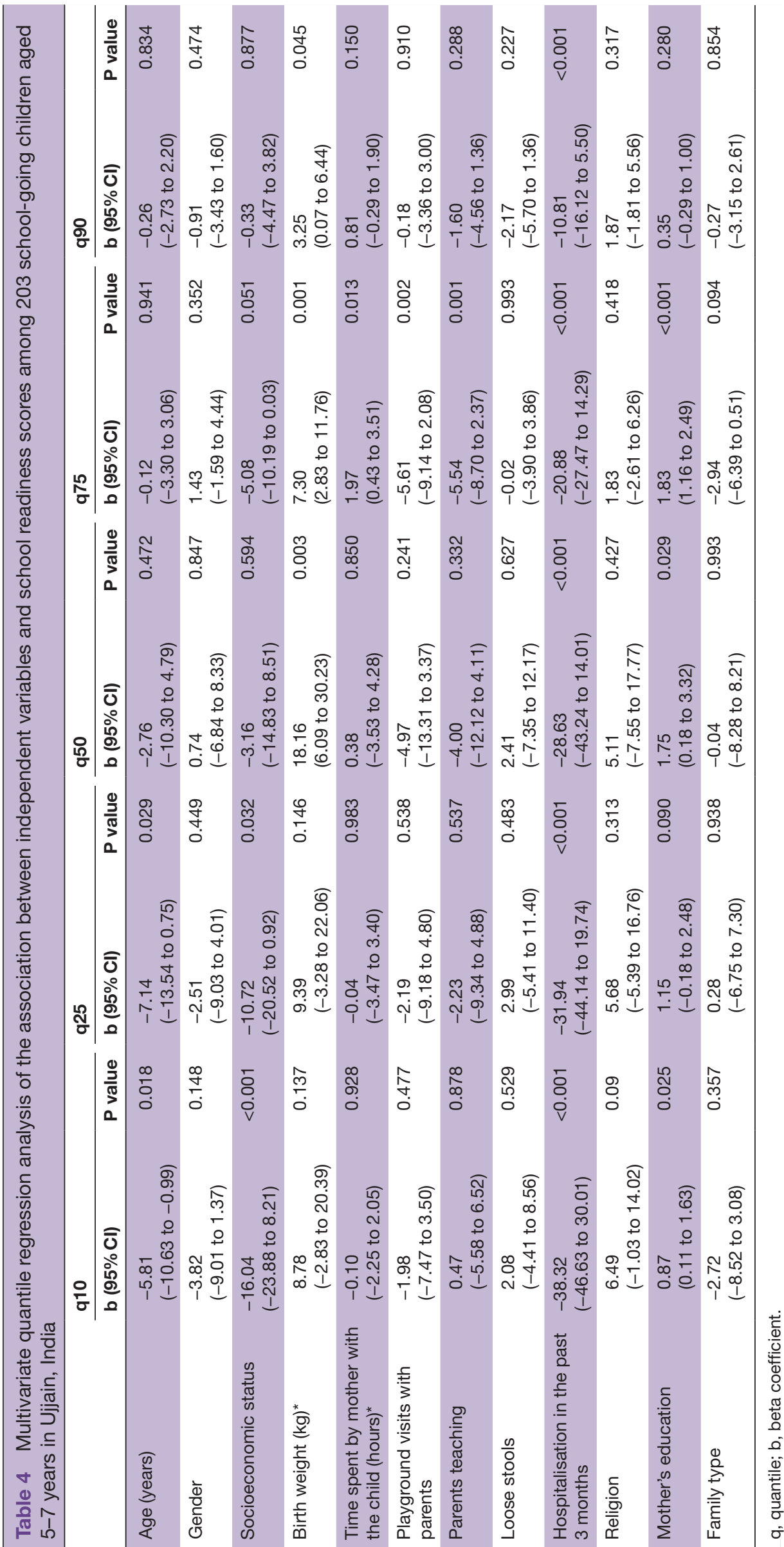


increases as birth weight decreases. ${ }^{28}$ Low birthweight children are one-third less likely to graduate from high school. ${ }^{28}$ The cognitive and social skills of children aged 3-7years can improve if their mothers and other caregivers spend time with them. ${ }^{29}$ Both education and recreational times have a significant positive effect on cognitive and social skills. ${ }^{29}$

The AEDC showed that development vulnerability in one or more domains decreased over time with significant gains in language, cognitive and communication skills, and general knowledge. ${ }^{17}$ However, progress in the domains of physical health and well-being, social competence and emotional maturity fluctuates over time. ${ }^{17}$ The development venerability of at-risk groups, however, has decreased over time by approximately $6 \% .{ }^{17}$ These findings show that school readiness can be improved in at-risk populations. As India has a large vulnerable population, ${ }^{4}$ improving school readiness can improve early childhood developmental outcomes.

\section{Methodological consideration}

The strength of our study is that we evaluated multiple covariate variables that might be associated with school readiness. A good internal validity was achieved for the school readiness subscale of DAS-II. However, our study has some weaknesses: the DAS-II scale is not validated in the Indian context. We chose urban English-medium schools to avoid translating the school readiness subscale. Therefore, our results are limited to the English-medium schools in a typical middle-class urban setting.

\section{CONCLUSIONS}

We identified multiple risk factors associated with school readiness in a typical Indian middle-class setting in urban English-medium schools. Lower quantile scores were achieved in matching letter-like forms, which measures complex visual-spatial processing, and phonological ability, which measures acquired verbal concepts. Focused interventions must be identified and designed to improve these skills in our settings. The arithmetic performance of children in this study could be evaluated in similar future studies.

Contributors AP conceived the idea and is the guarantor of the study. SS and VP collected the data. MS, MA, AM and AP supervised the collection of the data. SS, VP, MS, MA, AM and AP carried out data management. SS, MS, MA, AM and AP analysed the data. SS and AP drafted the manuscript. SS, VP, MS, MA, AM and $\mathrm{AP}$ read the drafts and provided feedback. All authors read and approved the final manuscript.

Funding The authors have not declared a specific grant for this research from any funding agency in the public, commercial or not-for-profit sectors.

Competing interests None declared.

Patient consent for publication Obtained.

Ethics approval The Institutional Ethical Review Board of RD Gardi Medical College, Ujjain, India, approved the study (IEC Ref No-459/2015).

Provenance and peer review Not commissioned; externally peer reviewed.

Data availability statement Data are available in a public, open access repository.
Open access This is an open access article distributed in accordance with the Creative Commons Attribution Non Commercial (CC BY-NC 4.0) license, which permits others to distribute, remix, adapt, build upon this work non-commercially, and license their derivative works on different terms, provided the original work is properly cited, appropriate credit is given, any changes made indicated, and the use is non-commercial. See: http://creativecommons.org/licenses/by-nc/4.0/.

\section{REFERENCES}

1. Blair C, Raver CC. School readiness and self-regulation: a developmental psychobiological approach. Annu Rev Psychol 2015;66:711-31.

2. High PC. American Academy of pediatrics Committee on early childhood, adoption, and dependent care and Council on school health. school readiness. Pediatrics 2008;121:e1008-15.

3. UNICEF. School readiness: a conceptual framework. 29. Three United Nations Plaza New York, New York 10017: United Nations Children's Fund Education Section Programme Division, 2012. https://www.unicef.org/earlychildhood/files/Child2Child_ ConceptualFramework_FINAL(1).pdf [Accessed 15 Jun 2019].

4. Chandra R. School readiness in India perspective, initiatives, practice and approaches. Journal of Indian Education 2017;XLII:23-37.

5. Kaul V, Bhattacharjea S, Chaudhary AB, et al. The India early childhood education impact study. New Delhi UNICEF; 2017: 1-186. http://www.unicef.in/earlymomentsmatter/Story-Full-Report-TheIndia-Early-Childhood-Education-Impact-Study.html [Accessed 22 Aug 2019].

6. Kaul V. Research in India on early childhood education and school readiness: some Learnings. In: Kaul V, Bhattacharjee S, eds. Early childhood education and school readiness in India quality and diversity. First. Singapore: Springer, 2019: 19-32. ISBN: 978-981-137006-9.

7. Kaul V, Ramachandran C, Upadhyaya GC, et al. Impart of early childhood education on retention in primary grades: a longitudinal study.. New Delhi, India National Council of Education Research and Training; 1993. http://ncert.nic.in [Accessed 22 Aug 2019].

8. Registrar General of India and census commissioner. census of India - 2011, Distric profile. Available: http://www.census2011.co.in/ census/district/302-ujiain.html [Accessed 15 Jun 2019].

9. National family health Survey-4, 2015-16 district fact sheet Ujjain Madya Pradesh. Mumbai Ministry of Health and Family Welfare, International Institute for Population Sciences; 2016: 1-4. http:// rchiips.org/NFHS/FCTS/MP/MP_FactSheet_435_Ujjain.pdf [Accessed 15 Jun 2019].

10. Oxford Poverty \& Human Development Initiative (OPHI). Global multidimensional poverty index report 2018 Chapter 2 Madhya Pradesh a case study, 2018. Available: https://ophi.org.uk/wpcontent/uploads/fv-India_ch_G-MPI_30Sept.pdf [Accessed 15 Jun 2019].

11. Krishnan S, Hatekar N. Rise of the new middle class in India and its changing structure. Econ Polit Wkly 2017;52:40-8.

12. Education portal of Madhya Pradesh, India, 2019. Available: http:// www.educationportal.mp.gov.in/Public/Schools/ssrs/State_School_ Block.aspx [Accessed 15 Jun 2019].

13. World Health Organization. Readings on diarrhoea: student manual. World Health Organization, 1992. Available: https://apps.who.int/iris/ handle/10665/40343 [Accessed 15 Jun 2019].

14. Sharma R. Revised Kuppuswamy's socioeconomic status scale: explained and updated. Indian Pediatr 2017;54:867-70.

15. Anon. Essentials of DAS-II assessment. New Jersey: John Wiley \& Sons, Inc, 2009: 1-416978-0-470-45047-5.

16. Yu K, Lu Z, Stander J. Quantile regression: applications and current research areas. J Royal Statistical Soc D 2003:52:331-50.

17. Australian early development census national report 2018. 50 Marcus Clark ST, Canberra act 2600, GPO box 9880, Canberra, ACT 2601, Australia The Department of Education and Training; 2018. https://www.aedc.gov.au/Websilk/Handlers/ResourceDocument. ashx?id=c3cf2764-db9a-6d2b-9fad-ff0000a141dd [Accessed 22 Aug 2019]. ISBN: 2206-284X

18. Janus M, Offord DR. Development and psychometric properties of the early development instrument (EDI): a measure of children's school readiness. Can J Behav Sci 2007;39:1-22.

19. Michalczyk K, Krajewski K, Preßler A-L, et al. The relationships between quantity-number competencies, working memory, and phonological awareness in 5- and 6-year-olds. Br J Dev Psychol 2013;31:408-24.

20. Piazza M. Neurocognitive start-up tools for symbolic number representations. Trends Cogn Sci 2010;14:542-51.

21. Östergren $R$, Träff $U$. Early number knowledge and cognitive ability affect early arithmetic ability. J Exp Child Psychol 2013;115:405-21. 
22. Palmer S. Working memory: a developmental study of phonological recoding. Memory 2000;8:179-93.

23. Henry LA, Messer D, Luger-Klein S, et al. Phonological, visual, and semantic coding strategies and children's short-term picture memory span. Q J Exp Psychol 2012;65:2033-53.

24. Ansari A, Purtell K, Gershoff E. Classroom age composition and the school readiness of 3- and 4-Year-Olds in the head start program. Psychol Sci 2016;27:53-63.

25. Cooper CE, Osborne CA, Beck AN, et al. Partnership instability, school readiness, and gender disparities. Sociol Educ 2011;84:246-59.
26. Arnold AP. Genetically triggered sexual differentiation of brain and behavior. Horm Behav 1996;30:495-505.

27. Magnuson K. Maternal education and children's academic achievement during middle childhood. Dev Psychol 2007:43:1497-512

28. Reichman NE. Low birth weight and school readiness. Future Child 2005:15:91-116.

29. Hsin A, Felfe C. When Does Time Matter? Maternal Employment, Children's Time With Parents, and Child Development. Demography 2014;51:1867-94. 